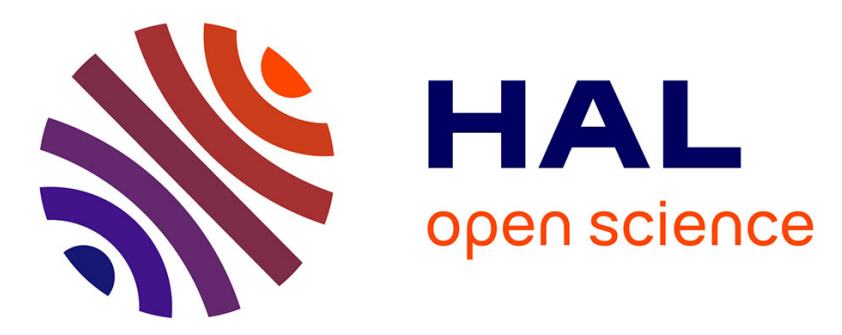

\title{
Converting sunlight into audible sound by means of the photoacoustic effect: The Heliophone
}

Nicolaas Bernardus Roozen, Christ Glorieux, L. Liu, Monika Rychtarikova, T. van Der Donck, A. Jacobs

\section{- To cite this version:}

Nicolaas Bernardus Roozen, Christ Glorieux, L. Liu, Monika Rychtarikova, T. van Der Donck, et al.. Converting sunlight into audible sound by means of the photoacoustic effect: The Heliophone. Journal of the Acoustical Society of America, 2016, 140 (3), pp.1697-1706. 10.1121/1.4962493 . hal-02895918

\section{HAL Id: hal-02895918 https://hal.science/hal-02895918}

Submitted on 10 Jul 2020

HAL is a multi-disciplinary open access archive for the deposit and dissemination of scientific research documents, whether they are published or not. The documents may come from teaching and research institutions in France or abroad, or from public or private research centers.
L'archive ouverte pluridisciplinaire HAL, est destinée au dépôt et à la diffusion de documents scientifiques de niveau recherche, publiés ou non, émanant des établissements d'enseignement et de recherche français ou étrangers, des laboratoires publics ou privés. 


\title{
Converting sunlight into audible sound by means of the photoacoustic effect: The Heliophone
}

\author{
N.B. Roozen, C. Glorieux, and L. Liu \\ Laboratory of Acoustics, Division Soft Matter and Biophysics, Department of Physics and Astronomy, KU Leuven, \\ Celestijnenlaan 200D, 3001 Leuven, Belgium \\ M. Rychtárikováa) \\ STU Bratislava, Faculty of Civil Engineering, Department of Building Structures, Radlinskeho 11, Bratislava, 81005 , \\ Slovak Republic \\ T. Van der Donck \\ Department of Materials Engineering, KU Leuven, Kasteelpark Arenberg 44, 3001 Leuven, Belgium
}

\author{
A. Jacobs \\ Overtoon, Platform for Sound Art, Luchtvaartsquare 19, 1070, Brussels, Belgium
}

(Dated: September 15, 2016)

One hundred and thirty-five years after Alexander Graham Bell and his assistant Charles Sumner Tainter explored the photoacoustic effect, and about 40 years after Rosencwaig and Gersho modeled the effect in a photoacoustic cell configuration, we revisit the phenomenon, in a "heliophone" device that converts sunlight into sound. The light is focused on a carbon blackened copper coated Kapton foil in an acoustic cell by means of a compound parabolic collimator, and its intensity is modulated by a mechanical chopper. A horn is employed to make the sound audible without electronic amplification. The description of the photoacoustic effect that was introduced by Rosencwaig and Gersho is extended to a cell-horn configuration, in which the periodically heated air above the foil acts as an oscillating piston, driving acoustic waves in the horn. The pressure in the cavity-horn assembly is calculated by considering the air layer piston as an equivalent volume velocity source. The importance of the carbon black (soot) layer to enhance light absorption, but above all to enhance the photothermal excitation efficiency, is elucidated by means of an experimentally supported physical model.

PACS numbers: 43.20.+g, 43.90.+v, 44.90.+c

\section{INTRODUCTION}

In the early days of telecommunication, Alexander Graham Bell experimented with the transmission of speech on a beam of light. The initial version of the device, called the photophone, was non-electric. At the transmitter side the speaker's voice put a mirror into vibration. A light beam was modulated by the vibrating mirror. At the receiver side, the intensity variations of the light beam were converted into sound as a result of the photoacoustic effect. The device consisted of a conical cavity in a brass housing closed by a flat plate of glass. The brass housing was connected to a hearing tube, which was to be held close to the ear of the receiver. The modulated light beam entered the cavity through the flat plate of glass. Alexander Graham Bell and his co-worker Mr. Tainter found that a teaspoonful

\footnotetext{
a) Also at Laboratory of Acoustics, Division Soft Matter and Biophysics, Department of Physics and Astronomy, KU Leuven, Celestijnenlaan 200D, 3001 Leuven, Belgium.
}

of lampblack put inside the cavity significantly reinforced the sound produced by the device. ${ }^{2}$

Just under 100 years later the theoretical basis of the photoacoustic effect was developed by Rosenswaig and Gersho ${ }^{3}$ The effect is based on the intermittent thermal heating of a medium that absorbes the energy of intensity modulated light. This causes an intermittent expansion of the absorbing medium. As a result, the medium launches an acoustic wave into its surroundings.

Developing simple classroom demonstrations of advanced concepts in physics is one of the missions of many professors and teachers in physics. Rush et al ${ }^{4}$ described an apparatus to demonstrate the photoacoustic effect using a slide projector, a mechanical chopper to periodically modulate the light beam, and a Fresnel lens to bundle light onto a funnel. The interior of the (closed) funnel was blackened by a flame. The purpose of the blackening is not mentioned in the article, although it is obviously required to absorb the light energy. The researchers made the sound audible by means of a hearing tube, which was connected to the funnel. The hearing tube had to be held close to the ear to hear a distinct sound caused by the 
photoacoustic effect.

Very recently (2015), Zhu et al ${ }^{5}$ described a photoacoustic device to turn the oscillating light from an incandescent light bulb into audible sound. The light bulb was driven by a sinusoidal AC power source with constant frequency of $50 \mathrm{~Hz}$, as well as by a square-wave chopped DC source with adjustable frequencies. The light of the bulb was incident upon a sealed cylindrical glass beaker. Half of the inner side of the beaker was coated by a soot layer of black smoke from burning kerosene. The sound was picked up by means of a microphone and electronically amplified. The authors reported that the sound level generated by the photoacoustic effect decayed over time, as a result of an increase of the mean temperature of the soot layer. This is physically explained by Rosencwaig and Gersho' s model, in which the pressure fluctuation is inversely proportional to the absolute temperature. Because of the continuous rise of the temperature of soot, the gas layer inside and just above the soot layer responds less easily to temperature fluctuations, causing an attenuation effect.

In the present work a heliophone device ${ }^{1}$ is proposed to convert sunlight into audible noise using the photoacoustic effect. The device proposed here uses a horn to amplify the sound in a passive manner. Numerical simulations are used to optimize the geometry of the device. Similar to the findings of Bell, ${ }^{2]}$ Rush et al ${ }^{4}$ and Zhu et al. $\frac{5}{5}$ experiments indicate that the photoacoustic effect is strongly increased by means of a layer of soot (carbon black). The layer of soot has two functions. First of all, soot is very effectively absorbing light. Secondly, it appears that the photoacoustic effect is significantly increased due to the extraordinary thermal properties of the soot layer, as elucidated by means of a physical model. The porosity and thermal conductivity of the soot layer are quantified.

The application of a horn to passively amplify the radiated sound is not new. It is widely applied in musical instruments. For technical apparatuses, for instance, it has been applied in a thermoacoustic device. ${ }^{6}$ However, to the best of our knowledge, the combined use of solar power and an acoustic horn to amplify the sound created by a photoacoustic device has not been shown before.

The paper is organized as follows. Section II treats the design of the Heliophone, including a discussion about the acoustical properties of the photo-acoustic cell and horn combination. Using a numerical model, the (passive) amplification effect of the horn is quantified. Section III discusses the experimental results. Section IV summarizes the conclusions of this work.

\section{THE DESIGN OF THE HELIOPHONE.}

In the proposed configuration of the Heliophone (Fig. 1. 2), sunlight is focused by means of a compound parabolic collimator (CPC) onto a photoacoustic cell. The azimuthal direction of the collimator is taken from a look-up table for the solar position, using the longitude of

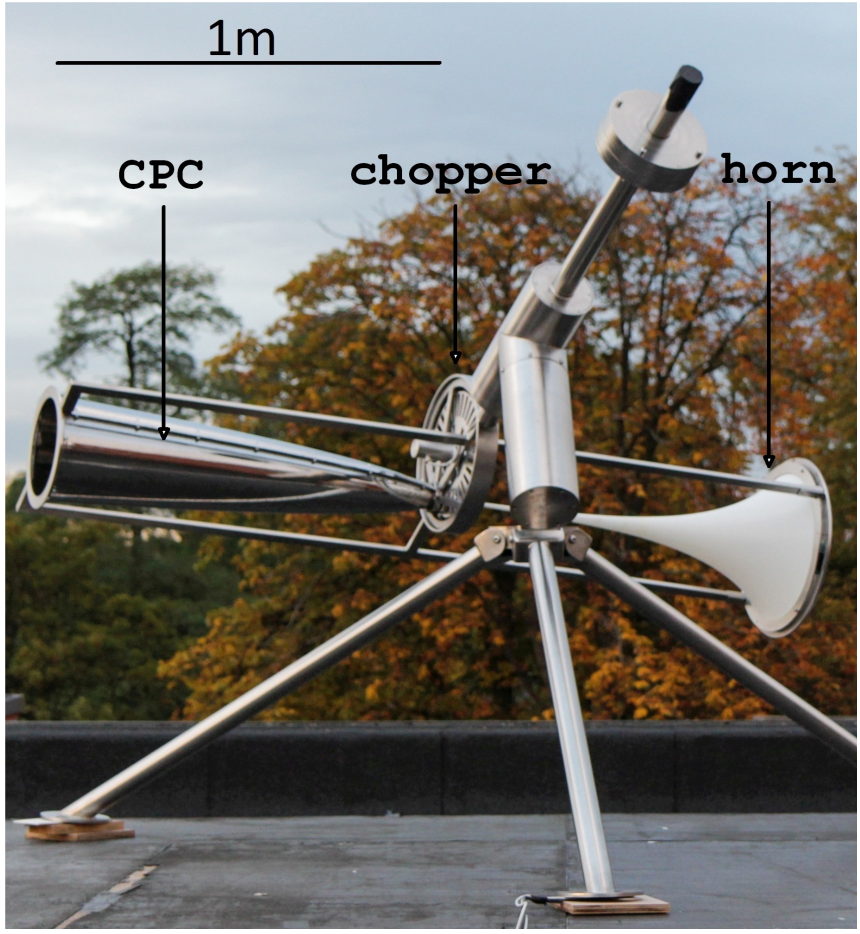

FIG. 1. (color online) Final realization of the Heliophone.

the site and the solar time as input parameters. The elevation is manually set to a fixed angle, in according with the season and latitude of the site. In the photoacoustic cell a Kapton@foil is present that was coated with copper and blackened with carbon soot from a candle flame. The body of the photoacoustic cell was made of plexiglas, to allow the chopped light beam to illuminate the carbon blackened copper coated Kapton foil. This foil acts as a photoacoustic transducer. The collimated sunlight is modulated by means of a rotating mechanical chopper. Due to optical absorption by the carbon black, a periodically varying heat flux is induced into the air above the surface. This causes pressure variations in the cell cavity at the chopper frequency and its harmonics. The cell is connected to an acoustic horn, which acts as an impedance matching device between the cavity and the open air environment, making the sound audible.

Details of the photoacoustic cell (Fig. 2) are given below. The foil (width of $9 \mathrm{~mm}$ ) was placed in the middle of the spherical cell cavity (inner diameter $\varnothing 15 \mathrm{~mm}$, radius $R_{s}=7.5 \mathrm{~mm}$ ). As the width of the foil is smaller than the diameter of the cell cavity, the lower and upper half of the cell cavity can communicate with each other. Inside the photo-acoustic cell the sound pressure level was uniformly distributed up to a frequency of about $f_{\max }=c / \lambda$, with $c$ being the speed of sound and with $\lambda$ equal to 2 times the typical dimension, giving $f_{\max } \approx 10 \mathrm{kHz}$. The thicknesses of the Kapton and copper layer are $65 \mu \mathrm{m}$ and $35 \mu \mathrm{m}$ respectively. The copper-Kapton layer was purchased from the Dupont ${ }^{\circledR}$ company (material trade name: Pyralux ${ }^{\circledR}$ ). The can- 

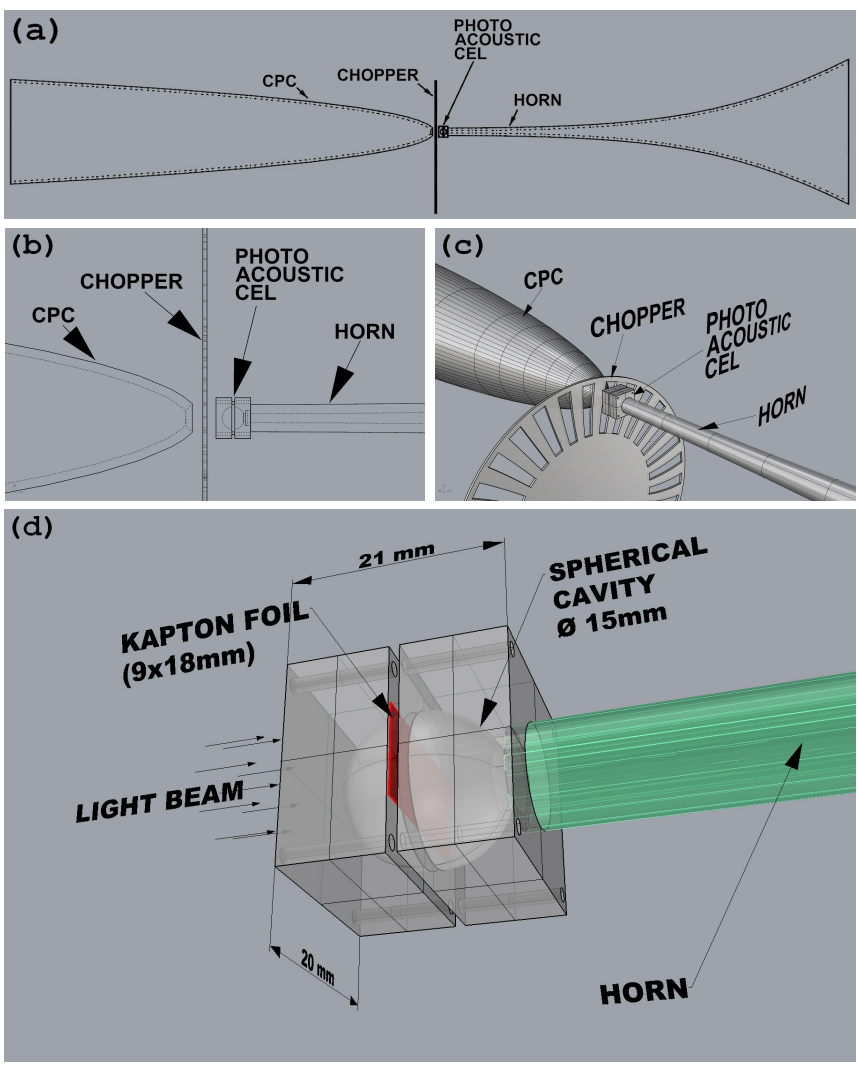

FIG. 2. (color online) Technical drawings of the Heliophone. $\mathrm{CPC}=$ compound parabolic collimator. (a) Cross-section of complete device. (b) Cross-section of the central part of the device. (c) 3D-view of the central part of the device. (d) $3 \mathrm{D}$-view of photo-acoustic cell with horn.

dle soot layer was deposited by swinging the Pyralux foil back and forth in the flame of an ordinary candle, with the copper side oriented to the flame.

This configuration of layers of material was chosen to have a large temperature oscillation amplitude at the soot-air interface. The Kapton and candle soot layer combination has a rather low thermal effusivity, resulting in high temperature oscillations. In addition, Kapton and candle soot have a good resistance against high temperatures. The copper layer allowed efficient steady state sinking of the produced heat away from the device, whilst at the same time did not affect the effusivity of the triple layer too much because of the fact that the copper layer was thermally thin at the modulation frequencies of interest (for copper with a typical thermal diffusivity $\alpha_{C u}=1.1 \cdot 10^{-4} \mathrm{~m}^{2} / \mathrm{s}$, the thermal diffusion length in the copper $\mu_{C u}=\sqrt{2 \alpha_{C u} / \omega}=600-80 \mu \mathrm{m}$ for frequencies between $100 \mathrm{~Hz}$ and $5000 \mathrm{~Hz}$ ).

To obtain a better understanding of the acoustics of the Heliophone, the device (i.e. cell and horn) was modeled by means of the boundary element method (BEM). The geometry of the cell with horn and a detail of the BEM mesh is shown in Fig. 3. The model exploits the axial symmetry of the device, and consists of 1051 nodes and 1050 elements. An acoustic point source with a volume source strength $Q=1 \mathrm{ml} \cdot \mathrm{s}^{-1}$ (arbitrary value) was used to assess the frequency dependent acoustic behavior of the cell-horn combination. The use of such an acoustic source is justified, because of two reasons. First of all a photo-acoustic source can be considered as a frequency independent acoustic volume source, as derived in Appendix A. Secondly, at frequencies well below the first acoustic resonance frequency of the cell $(10 \mathrm{kHz}$ for an inner radius $R_{s}=7.5 \mathrm{~mm}$ ), the use of a point source is allowed.
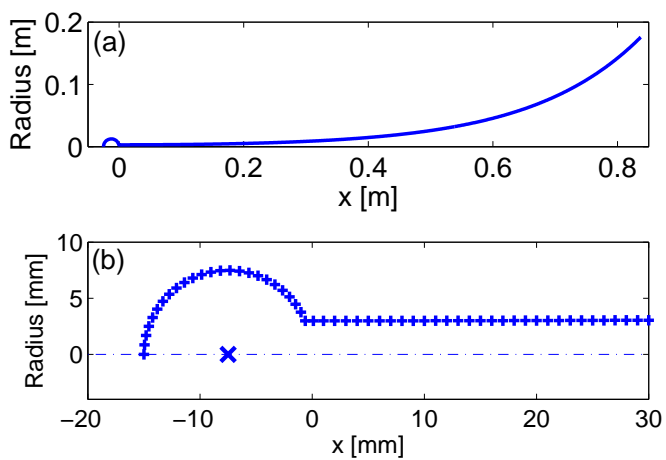

FIG. 3. (a) Closed cell with catenoidal horn geometry, cell radius $7.5 \mathrm{~mm}$, length horn about $0.84 \mathrm{~m}$, neck radius (at the beginning of the horn at $x=0$ ) of $3.0 \mathrm{~mm}$. (b) Detail of BEM mesh, + crosses indicating the model nodes and $\mathrm{x}$-cross at the center of the cell indicating the position of the point source.

Figure 4 shows the computed sound power spectrum (active part) for several values of the photo-acoustic spherical cell radii, $R_{s}$, varying from $6.3 \mathrm{~mm}$ up to 15.0 $\mathrm{mm}$. The horn geometry was kept fixed (catenodial horn, neck radius $3.0 \mathrm{~mm}$, length about $0.84 \mathrm{~m}$ ).

The acoustic response of the spherical photo-acoustic cell, combined with the horn, exhibits a number of resonance frequencies. The peaks at the higher frequencies can be associated with horn resonances. The cases with a larger photo-acoustic cell radius $\left(R_{s}=15.0 \mathrm{~mm}\right.$, $R_{s}=12.5 \mathrm{~mm}$ ) show a rather sharp peak at low frequencies, which can be associated with a Helmholtz resonance of the acoustic cell, with the horn fulfilling the role of the neck of the Helmholtz resonator. ${ }^{78}$

The Helmholtz resonance frequency of a volume $V$ attached to a diverging horn of length $L$ with variable cross section $S(x)$ is given by ${ }^{9}$.

$$
f_{H R}=\frac{c}{2 \pi} \sqrt{\frac{S(0)}{L_{e f f} V}}
$$

where $c$ is the speed of sound in air, $S(0)$ is the neck cross-sectional area (inlet of the horn at $x=0$ ) and $L_{\text {eff }}$ is the effective length given in first order approximation:

$$
L_{e f f}=\int_{o}^{L}[S(0) / S(x)] d x
$$



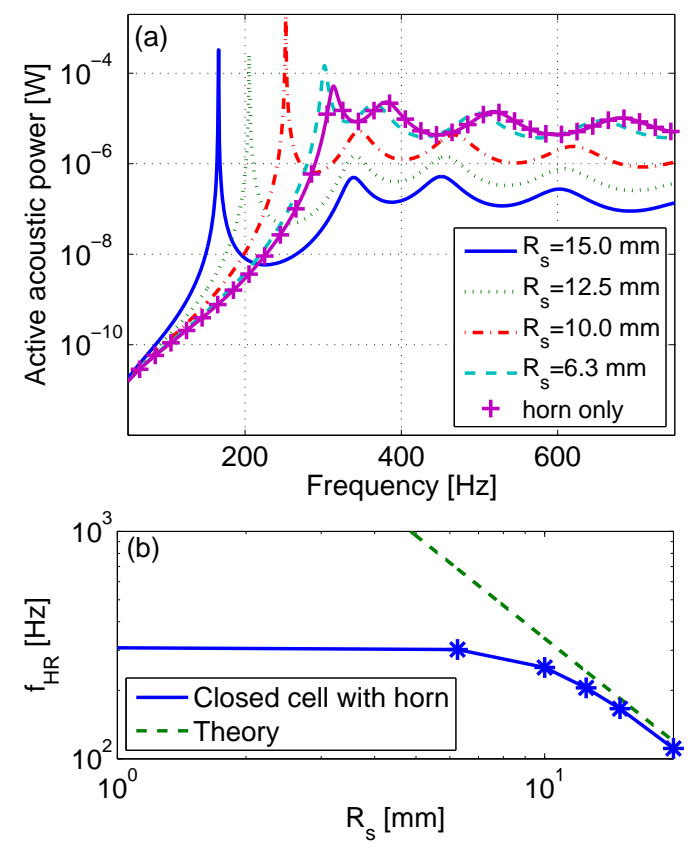

FIG. 4. (color online) (a) Simulated spectra of the sound power (active part), for an arbitrarily chosen volume source strength $Q=1 \mathrm{ml} \cdot \mathrm{s}^{-1}$. The radius of the photo-acoustic cell is varied from $6.3 \mathrm{~mm}$ to $15.0 \mathrm{~mm}$. Also the case of zero volume (i.e. horn only) is shown. (b) Dependence of the Helmholtz frequency of acoustic cell with horn on the cell radius $R_{s}$. Solid curve: numerically predicted. Dashed curve: theoretical relationship according to Eq. 1

This model ignores the end-corrections due to the movement of the air just outside the inlet and outlet of the horn. Eq. 2 is only valid for a Helmholtz resonance frequency which is well below the horn resonance frequencies. Indeed, Fig. 4 a shows that when reducing the radius $R_{s}$, the spectra converge to the case where the photoacoustic volume is zero (i.e. horn only). The Helmholtz resonance cannot become greater than the first resonance frequency of the horn $(316 \mathrm{~Hz})$, as can be seen from Fig. 4 b. Furthermore, the results from the BEM simulation (Fig. 4a) indicate that the radiated sound power level at both the Helmholtz resonance and at the horn frequencies increases with decreasing $R_{s}$.

The latter observation can be explained as follows. For a closed photo-acoustic cell, the sound pressure level in the closed cell is inversely proportional to the volume $V=$ $4 / 3 \pi R_{s}^{3}$ of the cell ${ }^{[3}$ The cell cavity can be considered as a compliance, which causes the sound pressure in the cavity to rise when the volume of the cavity is chosen smaller. Because the photo-acoustic source can be considered as a frequency independent volume source (cfr. Appendix A), the amount of acoustic power being generated inside the cell cavity (being the product of sound pressure and source volume velocity) is also higher, which is confirmed by the boundary element simulations (Fig. 4 a).

Thus, to increase the acoustic output of the device, the photoacoustic cell cavity should be chosen small. However, because of the possible risk of burning the foil, as well as practical limitations for a better focussing of the light beam, and possible adverse effects due to the attenuation effects as described by $\mathrm{Zhu}, 5$ a cell radius of 7.5 $\mathrm{mm}$ was chosen for the experimental implementation.

It should also be remarked that it is the total power of the light beam $\left(I_{0} S\right.$ in Eq. $\mathrm{A} 2$, Appendix $\mathrm{A}$ ) that effectively determines the acoustic volume source, not the light intensity $I_{0}$ of the beam.

To illustrate the effectiveness of the horn, a configuration is analyzed in which the photoacoustic cell is not connected to a horn, but radiates into free space through an opening. The sound power spectrum radiated by the opening of the photoacoustic cell without horn is given in Fig. 5 (dashed line). The level increases with frequency with $20 \mathrm{~dB} /$ decade, as expected for a frequency independent volume source and an opening that is much smaller than the acoustic wavelength. The sound power level radiated by the horn, also shown in Fig. 5 (solid line), is significantly higher for frequencies above $200 \mathrm{~Hz}$. The presence of the horn increases the radiated sound power with a factor varying between 30 and $40 \mathrm{~dB}$ at frequencies between 300 and $700 \mathrm{~Hz}$. This is consistent with the acoustic impedance matching improvement of the horn, which can be approximated by $10 \cdot{ }^{10} \log \left(S_{\text {out }, \text { horn }} / S_{\text {in,horn }}\right)$ for acoustic wavelengths much longer than the typical dimension of the horn $\left(S_{\text {out }, \text { horn }}^{1 / 2}\right)$.

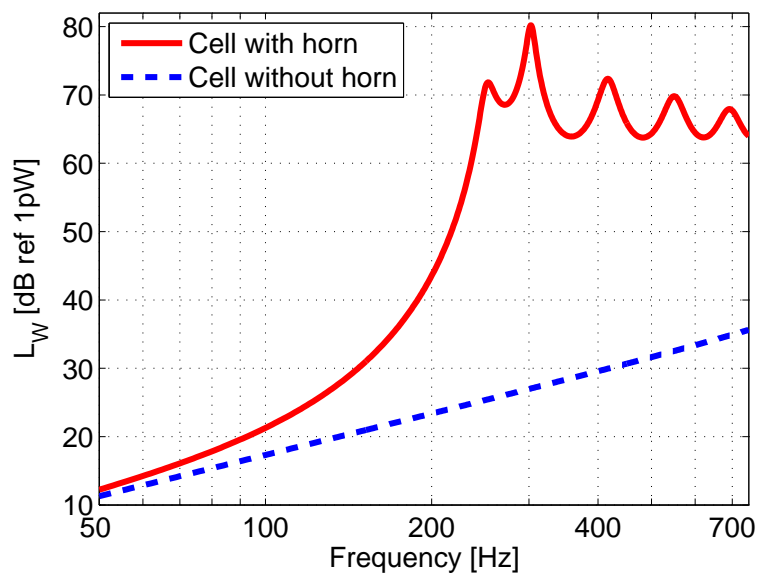

FIG. 5. (color online) Computed active sound power spectra for a photoacoustic cell with horn (solid line), horn length $0.84 \mathrm{~m}$, and for the photoacoustic cell, having a small opening, without horn (dashed line). Volume source strength $Q=1$ $m l \cdot s^{-1}, R_{s}=7.5 \mathrm{~mm}$.

\section{EXPERIMENTAL RESULTS}

Based upon the analysis results of the previous section, a closed photoacoustic cell and a prototype Heliophone (cell plus horn) was built and tested in an anechoic room (Section III A and section IIIB, respectively). For the 
laboratory measurements an artificial light source was employed. Outdoor measurements on the final version of the Heliophone that uses sunlight are discussed in Section III C. In all cases the chopper blade was driven by means of an externally powered electro-motor.

\section{A. Laboratory measurements closed photoacoustic cell}

As discussed in Section Ir ${ }^{214}$ researchers already found that blackening of the illuminated piece of material by means of soot is important for enhancing the photoacoustic effect. In this section photo-acoustic experiments on a closed acoustic cell (i.e. without horn) are discussed to elucidate the importance of the soot layer. Also the saturation effect that was found by $\mathrm{Zhu}$ et al., 5 and its importance with respect to the Heliophone, will be discussed.

\section{Equipment}

A blue light laser type LDM-450-1600 from Lasertack was used, emitting 450nm light with a nominal output power of $\mathcal{P}_{0}=1.6 \mathrm{~W}$. The laser was driven by a laser diode driver type LT-SHS-2500 from Lasertack. The photoacoustic cell cavity had a volume of $1.63 \mathrm{ml}\left(R_{s}=7.5\right.$ $\mathrm{mm})$.

A Bruel\&Kjaer type 4192 microphone, with associated equipment, was calibrated at $1000 \mathrm{~Hz}$ to within $0,2 \mathrm{~dB}$ using a Bruel\&Kjaer type 4231 Calibrator. This in turn was used to compare and correct a miniature Sennheiser MKE-2 microphone, which was chosen for sealed measurements in the cell cavity. Accuracy of $0.5 \mathrm{~dB}$ down to $10 \mathrm{~Hz}$ was achieved.

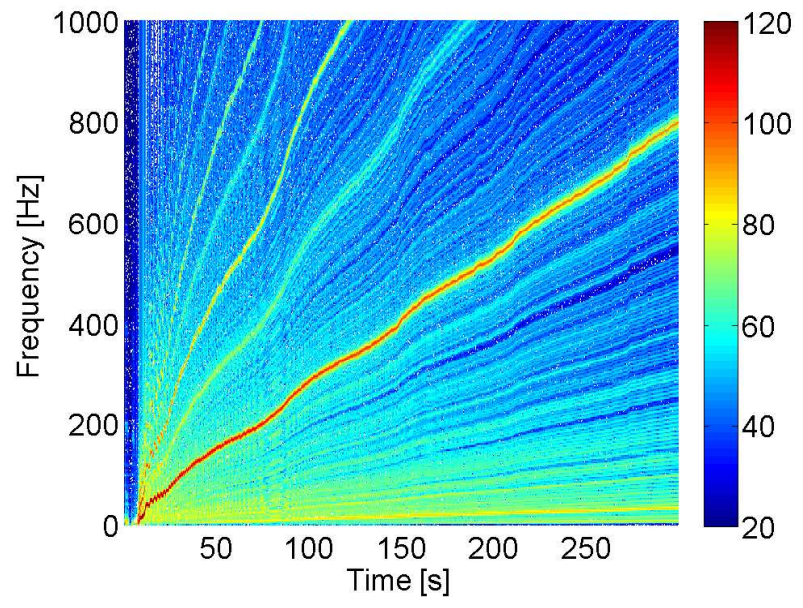

FIG. 6. (color online) Swept sine spectrogram of acoustic pressure in the closed photo-acoustic cell, porous carbon black - copper - Kapton sample. Color bar indicates the single sided power spectrum in $\mathrm{dB}$, ref $20 \mu \mathrm{Pa}$.

The mechanical chopper that was used to modulate the intensity of the light had equidistant light pass-

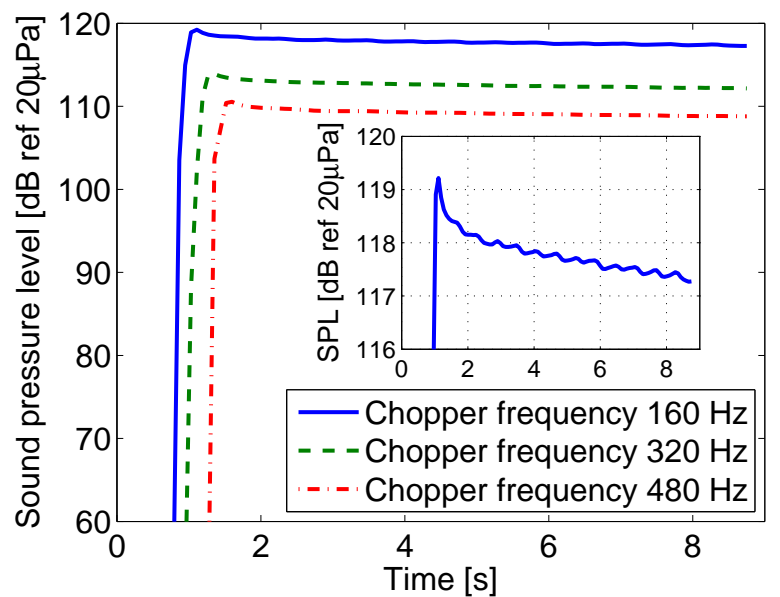

FIG. 7. (color online) Fundamental component of the sound pressure level in the closed photo-acoustic cell, porous carbon black - copper - Kapton sample, as a function of time, after turning on the light source. Chopper frequency $160 \mathrm{~Hz}$ (blue solid line), chopper frequency $320 \mathrm{~Hz}$ (dashed green line), and chopper frequency $480 \mathrm{~Hz}$ (red dashed-dotted line). The inset shows a zoom around the final maximum reached level.

ing slits with a width of $3.1 \mathrm{~mm}$ and equidistant light blocking strips with a width of $2.4 \mathrm{~mm}$. The thus obtained modulated light beam had a duty cycle $D$ of $3.1 /(3.1+2.4)^{*} 100=56 \%$. Assuming the light beam to be infinitesimally small in diameter, the resulting modulation is a true square wave. For such a signal (with unit amplitude), the Fourier amplitude of the fundamental component is equal to $\frac{2}{\pi} \sin \left(\frac{\pi D}{100}\right)=0.62$ (rms-value: $0.39)$.

\section{Acoustic measurement results}

The spectrogram of the photoacoustic signal was recorded while revving up the chopper blade. The results shown in Fig. 6 reveal the dominant fundamental component at the on-off-rhythm of the chopper, and its harmonics. Note that the fundamental frequency and the third (as well as the fifth) harmonic are most dominant in the spectrogram. The second and the fourth harmonic are also visible but less strong due to the on- and off time of the chopped light being almost equal. All other frequency components were more than $60 \mathrm{~dB}$ smaller as compared to the fundamental frequency.

Using a fixed chopper frequency, the on-set of the sound pressure level in the photo-acoustic cell, after turning on the light source, is shown in Fig. 7. which shows that the photo-acoustic signal is rather strong. In accordance with the findings of Zhu et al. $\frac{5}{5}$ it can be seen that the sound pressure level decays over time, as a result of an increase of the mean temperature of the soot layer and the air enclosed in the soot and above the soot layer. The effect is less than $2 \mathrm{~dB}$ in this experiment, which would infer a global temperature rise from room 
temperature $T_{0}=293 \mathrm{~K}$ to $10^{(2 / 20)} \cdot T_{0}=1.26 \cdot 293=$ $369 \mathrm{~K}$ or $100 \mathrm{deg}$ Celsius. The light source in this laboratory measurement had a light power which is of the same order of magnitude as that of the sun light incident upon the photo-acoustic cell during the in-situ measurements. Therefore it is expected that this attenuation effect will not be significantly higher for the Heliophone in practice as well (cfr. Section III C) showing a sound pressure level measured in front of the horn which is approximately 6 $\mathrm{dB}$ higher, denoting an in-situ light strength of about a factor 2 higher).

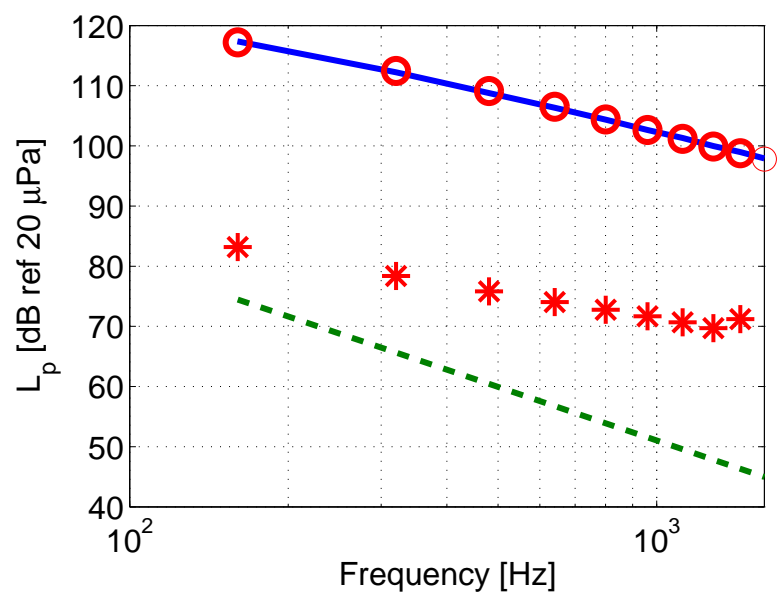

FIG. 8. (Color online) Measured sound pressure level in the closed photoacoustic cell (red O-markers) and predicted sound pressure level (solid blue line) for a porous carbon black - copper - Kapton sample. Measured SPL (red star symbols) and predicted SPL (dashed green line) for a copper-Kapton sample without soot, blackened by a marker (permanent marker, black, brand Lyreco). Experiments were performed using an acoustic cell with a volume of $1.63 \mathrm{ml}$, and a blue light source with a power of $1.6 \mathrm{~W}$.

Figure 8 (solid line) shows the frequency dependency of the sound pressure level of the fundamental Fourier component of the steady state signal (i.e. a few seconds after switching on the light source, see Fig. 7).

\section{Photoacoustic model}

For a better physical understanding of the photoacoustic signal generation, a model was built that took into account the oscillating heat transport in carbon blackened copper coated Kapton foil. For the configuration and modulation frequencies of interest, the thermal diffusion lengths in the air and in the multilayer surface were much smaller than the diameter of the light beam. Therefore a one-dimensional heat transfer model was adequate for describing the temperature variation in the system.10[11 The model involves harmonic solutions of the thermal diffusion equation in each layer. The layers are coupled by boundary conditions that ensure continuity of temperature and heat flux at each interface. The thermal properties of copper and Kapton that were used to compute the temperature fluctuations $\theta_{s}$ of the sample at its surface are given in Table I. From the computed temperature fluctuations $\theta_{s}$ the acoustic pressure variation $\Delta p$ can be computed using the theory of Rosencwaig and Gersho $\stackrel{3}{\text { : }}$

$$
\Delta p=\gamma p_{0} \frac{\int_{0}^{\infty} \theta(z) d z}{T_{0} h}
$$

where $\gamma$ is the ratio of specific heats, $p_{o}$ is the atmospheric pressure, $\theta(z)$ is the temperature fluctuation in the air above the sample, $z$ is the coordinate $(z=0$ the sample surface area), $T_{0}$ is the ambient temperature, and $h$ is the height of a cylindrical photo-acoustic cell. Assuming a temperature profile $\theta(z)=\theta_{s} \exp \left\{-(1+i) \frac{z}{\mu_{g}}\right\}$, where $\theta_{s}$ is the temperature fluctuation of the sample at its surface $(z=0)$ and $\mu_{g}$ is the thermal diffusion length of air, Eq. 3 can be written as

$$
\Delta p=\gamma p_{0} \frac{\theta_{s}}{T_{0}} \frac{S_{0}}{V_{0}} \frac{1}{\sqrt{2}} \mu_{g}=\gamma p_{0} \frac{\theta_{s}}{T_{0}} \frac{S_{0}}{V_{0}} \sqrt{\frac{\alpha_{g}}{\omega}}
$$

where $S_{0}$ is the surface of the sample that is exposed to the oscillating light beam and $V_{0}$ is the volume of the photo-acoustic cell $\left(h=S_{0} / V_{0}\right)$, and $\alpha_{g}=\mu_{g}^{2} \omega / 2$ is the thermal diffusivity of air.
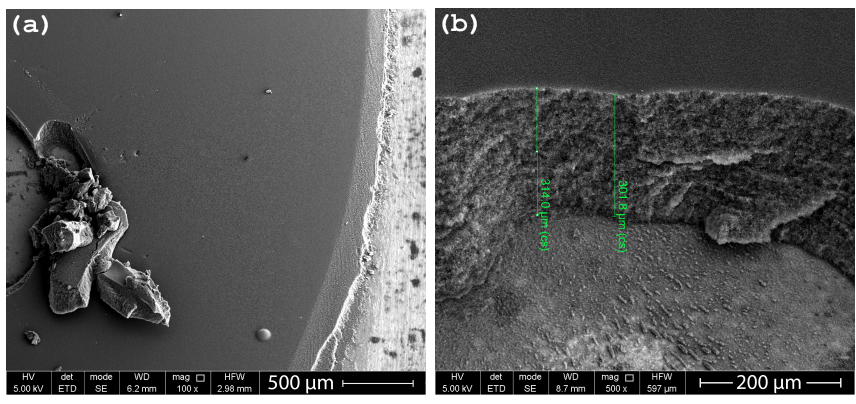

FIG. 9. SEM picture of soot layer of the carbon blackened copper coated Kapton foil measurements as discussed in Section III A A scratch was deliberately made in the soot, after the photo-acoustic measurements were performed. (a) Picture illustrating that the soot layer is relatively constant over a larger area. (b) Detail picture showing that the thickness was approximately $300 \mu \mathrm{m}$.

\section{Fit results of soot parameters}

The mass of the soot layer was measured by means of a high precision balance to be $(1.1 \pm 0.3) \mathrm{mg}$. The thickness of the soot layer was measured by means of a SEM electron microscope to be approximately $300 \mu \mathrm{m}$ (Fig. 9), being relatively constant over an area of 15 x $10 \mathrm{~mm}\left(R_{s}=7.5 \mathrm{~mm}\right)$. Together with a layer mass determination, this results in an effective density of (24 
$\pm 7 \mathrm{kgm}^{-3}$. Considering the bulk density of carbon $\left(2200 \mathrm{kgm}^{-3}\right)$, these values would correspond to a soot porosity $\phi=0.989 \pm 0.003$.

Given the thickness and density of the soot layer, the thermal properties of copper, Kapton and air and the laser power, we have used the measured sound pressure level spectrum in Fig. 8 to fit the thermal conductivity of the soot layer.

The effect of the porosity of the soot layer was implemented in the model via the effective density $\rho_{\text {eff }}=$ $(1-\phi) \rho_{\text {bulk }}$ (with $\rho_{\text {bulk }}$ the bulk density), which was then used to calculate the effective heat capacity, via $(\rho C)_{\text {eff }}=\rho_{\text {eff }} C_{\text {bulk }}$, the effective effusivity $\epsilon_{\text {eff }}=$ $\left(\rho_{e f f} C_{b u l k} \kappa_{s}\right)^{1 / 2}$ and the effective diffusivity $\alpha_{e f f}=$ $\kappa_{s} \rho_{\text {eff }}^{-1} C_{\text {bulk }}^{-1}$. The porosity $\phi$ of the candle soot layer, which is known to be mainly consisting of carbon black, and its thermal conductivity $\kappa_{s}$, were kept as fitting parameters. The cost function

$$
\chi^{2}=\sum_{i=0}^{n}\left(\frac{S P L_{\text {pred }}\left(\omega_{i}\right)-S P L_{\text {meas }}\left(\omega_{i}\right)}{S P L_{\text {meas }}\left(\omega_{i}\right)}\right)^{2}
$$

where $S P L_{\text {pred }}\left(\omega_{i}\right)$ is the predicted sound pressure level and $S P L_{\text {meas }}\left(\omega_{i}\right)$ is the measured sound pressure level, was minimized during the fit. The fitted values of porosity $\phi$ and the thermal conductivity $\kappa_{s}$ are listed in Table I. Figure 8 (red O-markers) shows a very good fit of the model onto the measurement data.

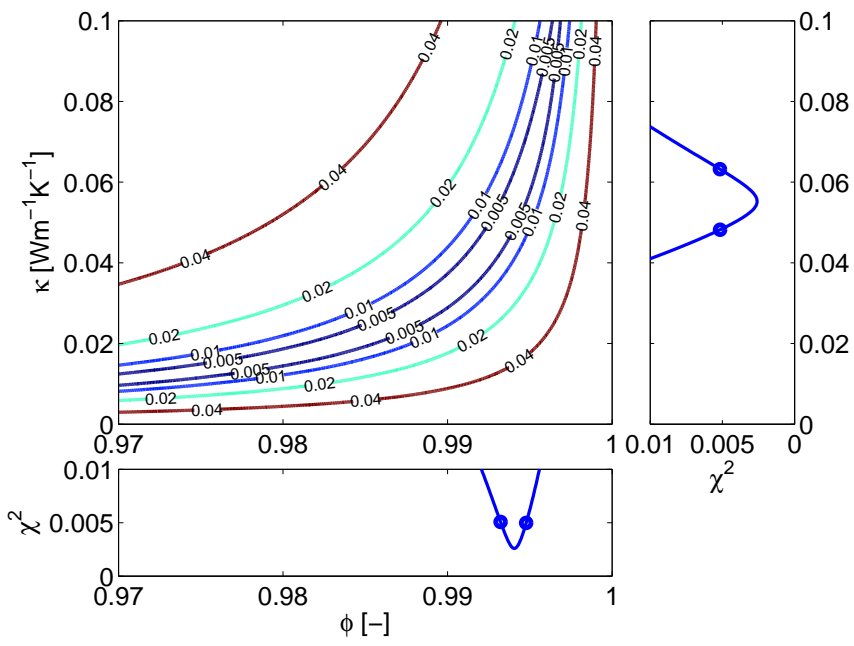

FIG. 10. (color online) Contour plot of the normalized error fitting cost function $\chi$ as defined by Eq. 5, as a function of chosen the porosity $\phi$ and the thermal conductivity $\kappa_{s}$ of the candle soot layer. Thickness candle soot layer: $300 \mu \mathrm{m}$, bulk modulus soot $2200 \mathrm{kgm}^{-3}$.

Together with the good match between the fit and the experimental data, the contour curves of $\chi^{2}$ versus $\phi$ and $\kappa_{s}$ in Fig. 10 reveal a unique minimum in the cost function, inferring a well-posed fit. The least squares errors $(\propto \text { fitting variances })^{12}$ are given in Table I. using the number of measurement points $(N-P)$ to be 1 (which is a conservative approach).
The fitted value for the thermal conductivity $\kappa_{s}=$ $(0.06 \pm 0.01) \mathrm{Wm}^{-1} \mathrm{~K}^{-1}$ of the soot layer turns out to be only twice of the thermal conductivity of air. The fitted porosity $\phi=0.994 \pm 0.001$ is very high, but consistent with the one determined from the mass to volume ratio $0.989 \pm 0.003$

The effect of changes in the assumed bulk density of soot appears to have only influence on the resulting estimate of the soot porosity $\phi$; the estimate for thermal conductivity $\kappa_{s}$ is not affected. Decreasing this bulk density by $x \%$ will simply increase the value of $(1-\phi)$ by $x$ $\%$, and vice versa. So, effectively, when assuming for instance a soot bulk density of $1880 \mathrm{kgm}^{-3}$, instead of of $2200 \mathrm{kgm}^{-3}$, yields $\phi=0.993$ instead of $\phi=0.994$, which shows that the effect is not very strong. Nevertheless, the accuracies given in Table $\mathbb{1}$ should be treated as lower bound uncertainties.

To quantify the importance of the candle soot layer for enhancing the photoacoustic light-to-sound conversion efficiency, a measurement was done in the closed cell using the same copper coated Kapton foil material, but without candle soot. The foil material was illuminated at the copper coated side. In order to have a good absorption of the light beam energy, the copper coating was blackened by means of a permanent marker, black, brand Lyreco. The measurement results are shown in Fig. 8 (red dash-dotted curve with star-markers). A drop of the sound pressure level 30-35 dB can be observed.

The effect of a change in optical reflection coefficient, blackening of the Kapton foil by means of soot or by means of a permanent marker was found not to be very significant. Measuring the amount of light reflected from the Kapton foil, using spatially averaging over a hemisphere, stayed well below $0.1 \%$ and $0.2 \%$, respectively. Thus the amount of light being absorbed is approximately $99.9 \%$ and $99.8 \%$, respectively, which is about equal.

Using the oscillating heat transport model combined with the model of Rosencwaig and Gersho (Eq. 4), the theoretical sound pressure level in the photoacoustic cell was predicted for the copper coated Kapton foil material without candle soot, using the material properties as listed in Table I The result is shown in Fig. 8 (dashed green line). In this case an absorption coefficient of 99.8 $\%$ was used. The sound pressure level in the photoacoustic cell are found to decrease by 40 to $50 \mathrm{~dB}$ in the frequency range from 30 to $1000 \mathrm{~Hz}$, as compared to the candle soot carbon blackened copper coated Kapton foil simulations and measurements. The difference between the theoretical prediction and the measurement on the permanent marker blackened foil is likely to be caused by the fact that the blackening of the sample by means of a marker also induces some additional photoacoustic effects which are not accounted for in the theoretical model. 
TABLE I. Material properties of the multilayered sample. Used relationships: effective heat capacity, via $(\rho C)_{e f f}=\rho_{\text {eff }} C_{b u l k}$, the effective effusivity $\epsilon_{e f f}=\left(\rho_{e f f} C_{b u l k} \kappa_{s}\right)^{1 / 2}$ and the effective diffusivity $\alpha_{e f f}=\kappa_{s} \rho_{e f f}^{-1} C_{b u l k}^{-1}$.

\begin{tabular}{|c|c|c|c|c|c|c|c|}
\hline & $\begin{array}{l}\text { Thickness } \\
{[\mu \mathrm{m}]}\end{array}$ & $\begin{array}{l}\text { Density } \\
\rho \\
{\left[\mathrm{kgm}^{-3}\right]}\end{array}$ & $\begin{array}{l}\text { Porosity } \\
\text { factor } \phi \\
{[-]}\end{array}$ & $\begin{array}{l}\text { Thermal } \\
\text { conduc- } \\
\text { tivity } \\
{\left[\mathrm{Wm}^{-1} \mathrm{~K}^{-1}\right]}\end{array}$ & $\left|\begin{array}{lr}\text { Specific reat } \\
\text { capacity } & C_{S} \\
\left.\left[\mathrm{~J} \mathrm{~kg}^{-1} \mathrm{~K}^{-1}\right)\right]\end{array}\right|$ & $\left|\begin{array}{ll}\text { Thermal } & \\
\text { effusivity } & \epsilon_{s} \\
{\left[\mathrm{Jm}^{2} \mathrm{~K}^{-1} \mathrm{~s}^{-1 / 2}\right.}\end{array}\right|$ & $\begin{array}{l}\text { Thermal } \\
\text { diffusivity } \\
\alpha\left[\mathrm{m}^{2} \mathrm{~s}^{-1}\right]\end{array}$ \\
\hline Air & & 1.19 & & 0.024 & 1006 & 5.4 & $1.99 \cdot 10^{-5}$ \\
\hline $\begin{array}{l}\text { Porous } \\
\text { carbon } \\
\text { black } \\
\text { layer }\end{array}$ & 40 & $\begin{array}{l}2200 \\
\text { (bulk } \\
\text { value) }\end{array}$ & $\begin{array}{l}0.994 \\
\pm \quad 0.001 \\
\text { (from } \\
\text { fit) }\end{array}$ & $\begin{array}{l}0.06 \pm 0.01 \\
\text { (from fit) }\end{array}$ & $\begin{array}{l}710 \quad \text { (bulk) } \\
4 \text { (effective) }\end{array}$ & 25 (effective) & $\begin{array}{l}6 \quad \cdot 10^{-6} \\
\text { (effective) }\end{array}$ \\
\hline $\begin{array}{l}\text { Copper } \\
\text { layer }\end{array}$ & 35 & 8960 & & 400 & 390 & $3.7 \cdot 10^{4}$ & $1.1 \cdot 10^{-4}$ \\
\hline $\begin{array}{l}\text { Kapton } \\
\text { layer }\end{array}$ & 65 & 1420 & & 0.12 & 1090 & 430 & $7.8 \cdot 10^{-8}$ \\
\hline
\end{tabular}

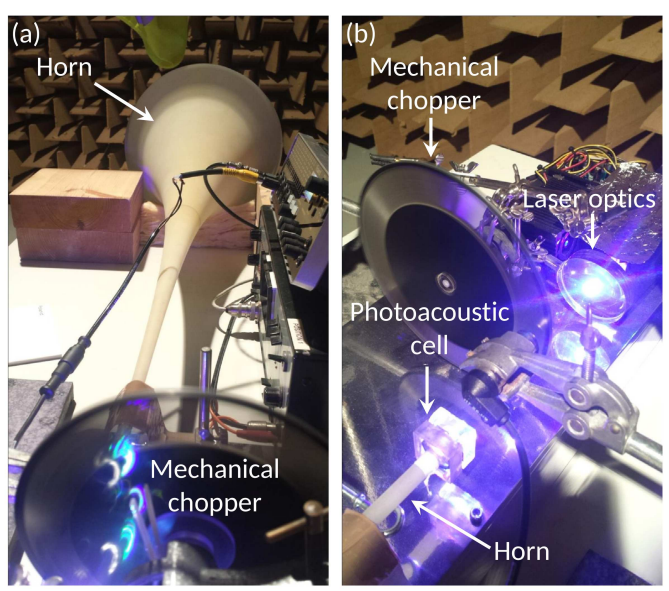

FIG. 11. (color online) laboratory experiments on Heliophone. (a) horn and chopper. (b): lasers as an artificial light source, chopper, photoacoustic cell, first part (neck) of the horn.

\section{B. Laboratory measurements photoacoustic cell connected to a horn}

This section discusses laboratory experiments (Fig. 11 of the photoacoustic cell connected to a horn. The sound pressure level was measured at the very end of the horn on the axis of symmetry, by means of a calibrated Bruel\&Kjaer microphone type 4192, in a semi-anechoic room. The artificial light source consisted of three lasers, emitting spatially overlapping green, red and blue light beams. The combined DC (i.e. non-chopped) light power of these lasers was determined to be $\mathcal{P}_{0}=0.74 \mathrm{~W}$ by means of a Thorlabs ${ }^{\circledR}$ light power meter model PM100D. The beam diameter was about $5 \mathrm{~mm}$. Similar chopper frequency sweeps were carried out as in Section III A. Figure 12 shows the frequency dependence of the fundamental frequency component.

Figure 12 also shows a theoretical prediction, which used the same thermal model and material as in Section III A, in combination with an equivalent acoustic volume source source and BEM model as described in Section III.

The predicted trends in frequency dependency corre- spond reasonably well with the experimental results. At frequencies higher than $350 \mathrm{~Hz}$, all peak frequencies that correspond to the horn resonances are adequately predicted. The predicted Helmholtz resonance at $250 \mathrm{~Hz}$ and the first horn resonance frequency at $300 \mathrm{~Hz}$ are hardly visible in the experimental data. The predicted peak is probably overestimated in the simulations because viscous losses $\frac{13}{13}$ were not taken into account in the model.

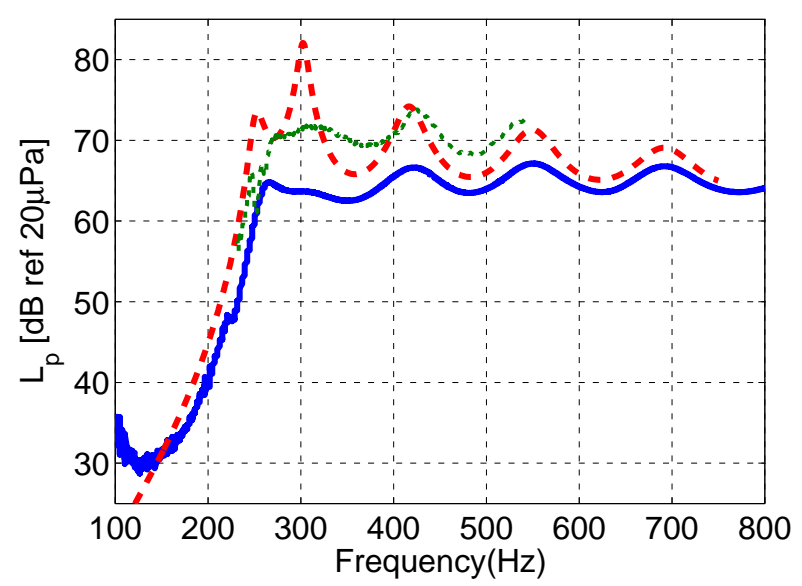

FIG. 12. (color online) Fundamental component of the sound pressure level in front of the horn, measured in the laboratory using a light beam of $0.74 \mathrm{~W}$ (solid blue line), measured in-situ using sunlight (dotted green line), and predicted (red dashed line). $R_{s}=7.5 \mathrm{~mm}$.

\section{In-situ measurements photoacoustic cell connected to a horn using sun-light}

In the following we discuss a measurement with the Heliophone that was carried out around noon time on a sunny day in May. The acoustic pressure was measured at the end of the horn, similar to the experiments in the laboratory (as described in Section III B). The Heliophone as shown in Fig. $2 \mathrm{~d}$ was used for this purpose, sweeping the chopper blade from a maximum achievable rotational speed down to stand-still. The slits in the chopper blade (Fig. 13, using the outer part of the chop- 


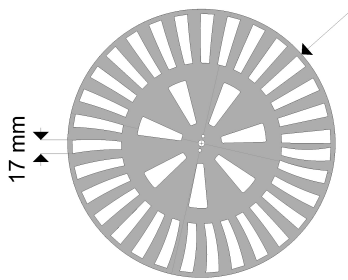

$\mathrm{R}=166 \mathrm{~mm}$

FIG. 13. Chopper blade with varying slit shape and slit size (31 slits).

per with 31 slits) vary slightly in shape and width, causing a slight frequency modulation of the chopping process, which resulted in a specific sound being generated by the Heliophone. The spectrogram (Fig. 14) illustrates this specific sound, showing multiple discrete frequencies (sub-tones) being generated. The spectrogram also illustrates that the fundamental frequency is the strongest, followed by the third, the fifth and the seventh harmonic, as expected (cfr. Section III A, Fig. 6). During the beginning of the sweep (i.e. for $t<13 \mathrm{~s}$, at a rotational speed of about $1050 \mathrm{rpm}$, fundamental frequency equal to $540 \mathrm{~Hz}$ ), the sound pressure in front of the horn was measured to be $79 \mathrm{~dB}(\mathrm{~A})$ (main frequency component $540 \mathrm{~Hz}$ ). In practice, the Heliophone can be heard up to a distance of 2 - 3 meters, operating the device in a city with an estimated outdoor sound pressure SPL-range of at least $5055 \mathrm{~dB}$ in the $500 \mathrm{~Hz}$ octave band.

Figure 12 (dotted line) shows the frequency dependency of the sound pressure level of the fundamental Fourier component, extracted from the spectrogram. This figure (solid line) shows the results from the laboratory measurements (discussed earlier in Section III B as well. Their shapes are very similar, only the levels are different. The Heliophone signal strength being 6-8 dB higher than the one in the laboratory experiment infers that the collected sunlight power was double as large (i.e. somewhat less than 2 Watt) as the laser power used in the laboratory experiment (0.74 Watt). As compared to the numerical prediction (dashed line), the measurements in the laboratory and in-situ compare well in terms of their shape and amplitude, although at lower frequencies the predictions are largely overestimated because viscous losses that are not taken into account in the model (as mentioned in Section IIIB.

\section{CONCLUSIONS}

Audible sound with a sound pressure level of $79 \mathrm{~dB}(\mathrm{~A})$ ref $20 \mu \mathrm{Pa}$ was generated by the Heliophone, consisting of a compound parabolic collimator to concentrate the sunlight, a mechanical chopper, a photoacoustic cell and a horn. The sample in the photoacoustic cell consisted of a Kapton foil which was coated with copper and blackened with carbon soot. The horn acts as an impedance matching device between the photoacoustic cell and the open air environment, making the sound audible.

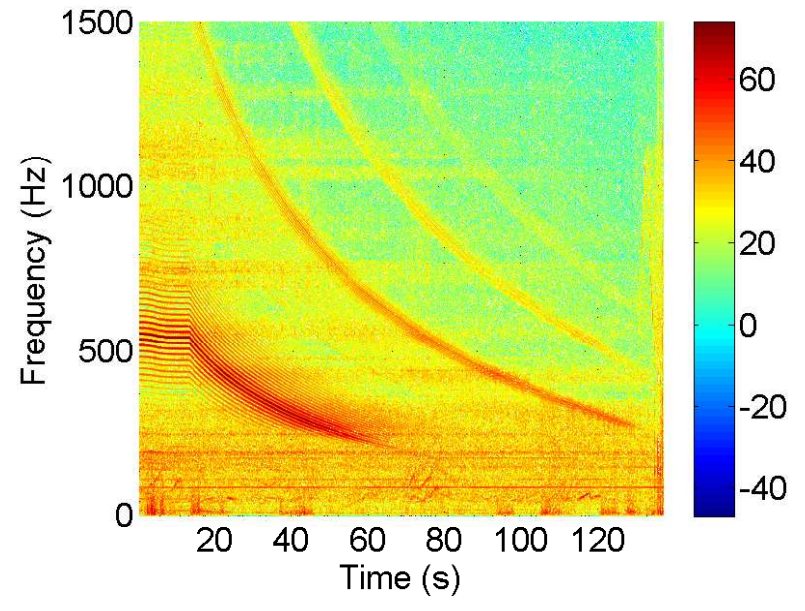

FIG. 14. (color online) Spectrogram of acoustic pressure measured in front of horn. Rotation speed of chopper is at first constant, and then reduces gradually to lower speeds. The color bar indicates the single sided power spectrum in $\mathrm{dB}$, ref $20 \mu \mathrm{Pa}$.

The magnitude and frequency dependence of the photoacoustic signal are well fitted by a theoretical model that combines the calculation of air surface temperature oscillations with an equivalent volume source model in a boundary element simulation.

It is shown that using a soot layer is not only adequate to maximize light absorption, but also to increase the photoacoustic light-to-pressure conversion efficiency as a result of the very high porosity and the very low thermal conductivity of the soot layer. The porosity of the soot layer was estimated at $(99.4 \pm 0.1) \%$ and the thermal conductivity at a remarkably low value of $(0.06$ $\pm 0.01) \mathrm{Wm}^{-1} \mathrm{~K}^{-1}$. Measurements without soot, whilst approximately retaining the high absorption of light, indicate that the particularly low thermal effusivity of the soot layer increases the photoacoustic signal generation efficiency by $30-35 \mathrm{~dB}$.

In addition to the crucial aspect of using a carbon black candle soot layer in the photoacoustic cell, the horn also contributed significantly to the audibility of the sound being generated. The horn increases the radiation efficiency of the photoacoustic cell by a factor varying between 30 and $40 \mathrm{~dB}$ at frequencies between 300 and 700 $\mathrm{Hz}$, as compared to a freely radiating photoacosutic cell with an opening.

\section{Acknowledgments}

The authors are grateful for the valuable brainstorming sessions with Julie Vandenbroucke (Arteconomy), for the optics calculations of the CPC (Jonas Doevenspeck, Kristof Peeters), the technical and mechanical realisation (Culture Crew, Imal Fablab, glass workshop KU Leuven and Dennis Pohl), the production team (Overtoon), for the possibility to exhibit Heliophone to a wide au- 
dience at STUK - Leuven, Bas Möllenkramer and Petra Kroon for their suggestions concerning the manuscript, and IWT Belgium for financial support of this research (CICI-project 130737 'Photophon').

\section{APPENDIX A: PHOTO-ACOUSTIC MODELING ASPECTS}

The oscillating temperature field $\theta$ in the air layer above the sample, averaged over the sample surface $A$, can be expressed as ${ }^{1415} \theta(t, z)=\theta_{s} \exp (i \omega t) \exp \left(-\sigma_{g} z\right)$, with $z$ the axial coordinate $(z=0$ being the surface of the sample), $t$ the time, $\omega$ the angular modulation frequency, $\theta_{s}$ is the temperature of the solid at its surface, $\sigma_{g}=(1+i) \sqrt{\frac{\omega}{2 \alpha_{g}}}=\frac{(1+i)}{\mu_{g}}$, where $\alpha_{g}=\kappa_{g} / \rho_{g} C_{g}$ is the thermal diffusivity of air, $\kappa_{g}$ is the thermal conductivity of air, $\rho_{g}$ is the density of air, $C_{g}$ is the specific heat of air, and $\mu_{g}=\sqrt{2 \alpha_{g} / \omega}$ the thermal diffusion length of air. The induced thermal expansion variations can be translated to an equivalent acoustic point source with volume velocity $Q$, via

$$
Q(t)=\frac{A}{T_{0}} \frac{\partial}{\partial t}\left(\int_{0}^{\infty} \theta(t, z) d z\right)=A \frac{i \omega \theta_{s}}{\sigma_{g} T_{0}} \exp (i \omega t)
$$

with $T_{0}$ the average temperature of the air.

For a thermally thick and optically opaque layer (in this case carbon black) illuminated with an intensity $I(t)=I_{0} \exp (i \omega t)$, considering that the thermal effusivity of air is much smaller than the one of the solid layer, the layer-air interface temperature oscillation amplitude is given by $\theta_{s}=I_{0} / \kappa_{s} \sigma_{s}$, with $\kappa_{s}$ the thermal conductivity of the layer material, the acoustic volume source is given by

$$
Q(t)=A \frac{i \omega I_{0}}{\kappa_{s} \sigma_{s} \sigma_{g} T_{0}} \exp (i \omega t)=A \frac{2 i I_{0} \sqrt{\alpha_{g}}}{\epsilon_{s} T_{0}} \exp (i \omega t)
$$

where $\epsilon_{s}=\sqrt{\kappa_{s} \rho_{s} C_{s}}$ is the thermal effusivity of the sample material, $\rho_{s}$ is the density of the sample, and $C_{s}$ is the specific heat of the sample. Note that the magnitude of the volume source $Q$ in the above equation is independent of frequency.

The use of a point source is valid for frequencies at which the acoustic wavelength is much greater than the typical dimension of the acoustic cell.

\section{REFERENCES}

\footnotetext{
${ }^{1}$ See http://www.heliophone.earth
}

${ }^{2}$ A. G. Bell, The production of sound by radiant energy, Science 2 (48) (1881) 242-253.

URL http ://www . jstor .org/stable/2900190

${ }^{3}$ A. Rosencwaig, A. Gersho, Theory of photoacoustic effect with solids, Journal of Applied Physics 47 (1) (1976) 64-69, 1977. URL <GotoISI>://WOS : A1976BC60500011

${ }^{4}$ W. F. Rush, J. E. Heubler, Photo-acoustic effect demonstration, American Journal of Physics 50 (7) (1982) 669-669.

URL ://WOS : A1982NX46100026

${ }^{5}$ Z. Zhu, L. Du, Y. Zhang, S. Wang, H. Zhou, W. Gao, Hearing light from an incandescent bulb, European Journal of Physics 36 (1).

URL : //WOS : 000349795400003

${ }^{6}$ T. J. Hofler, J. A. Adeff, An optimized miniature hofler tube, Acoustics Research Letters Online 2 (1) (2001) 37-42.

URL : //INSPEC: 6942168

${ }^{7}$ N. C. Fernelius, Helmholtz resonance effect in photoacoustic cells, Applied Optics 18 (11) (1979) 1784-1787, 51.

URL <GotoISI> ://WOS : A1979GX78300022

${ }^{8}$ O. Nordhaus, J. Pelzl, Frequency-dependence of resonant photoacoustic cells - the extended helmholtz resonator, Applied Physics 25 (3) (1981) 221-229, 60.

URL <GotoISI> ://WOS : A1981LX22300005

${ }^{9}$ A. Hirschberg, "Introduction to Aero-acoustics of Internal Flows", in "Aerodynamic Noise from Wall-Bounded Flows", Editors: J. Anthoine and J. Christophe, Lecture Series 2009-03, Von Karman Institute for Fluid Dynamics, Rhode-St-Genese, Be. (2009).

${ }^{10}$ H. P. Hu, X. W. Wang, X. F. Xu, Generalized theory of the photoacoustic effect in a multilayer material, Journal of Applied Physics 86 (7) (1999) 3953-3958, 55. URL <GotoISI> : //WOS : 000082652400073

${ }^{11} \mathrm{C}$. Glorieux, J. Fivez, J. Thoen, Photoacoustic investigation of the thermal-properties of layered materials - calculation of the forward signal and numerical inversion procedure, Journal of Applied Physics 73 (2) (1993) 684-690, 63. URL <GotoISI> : //WOS : A1993KG47600026

${ }^{12}$ R. Salenbien, R. Cote, J. Goossens, P. Limaye, R. Labie, C. Glorieux, Laser-based surface acoustic wave dispersion spectroscopy for extraction of thicknesses, depth, and elastic parameters of a subsurface layer: Feasibility study on intermetallic layer structure in integrated circuit solder joint, Journal of Applied Physics $109(9), 10$ URL <GotoISI> : //WOS : 000290588500013

${ }^{13} \mathrm{~T}$. Starecki, Loss-improved electroacoustical modeling of small helmholtz resonators, Journal of the Acoustical Society of America 122 (4) (2007) 2118-2123, starecki, Tomasz. URL : //WOS: 000250027000028

${ }^{14} \mathrm{M}$. Chirtoc, Investigation of layered systems and temperaturedependent thermophysical characterization by photothermal methods with periodic excitation, in: E. M. Moares (Ed.), Thermal Wave Physics and Related Photothermal Techniques: Basic Principles and Recent Development, Transworld Research Network, Kerala, 2009, Ch. 2, pp. 29-63, iSBN 978-81-7895-401-1.

${ }^{15} \mathrm{M}$. Chirtoc, Investigation of layered systems and temperaturedependent thermophysical characterization by photothermal methods with periodic excitation, in: 15th International Conference on Photoacoustic and Photothermal Phenomena, Vol. 214 of Journal of Physics Conference Series, 2010, 1742-6588. URL ://WOS : 000287820700005 